\title{
Applications of the pedicled vastus lateralis flap for patients with complicated pressure sores
}

\author{
AB Schmidt ${ }^{1}$, G Fromberg $^{1}$ and M-H Ruidisch ${ }^{2}$ \\ ${ }^{1}$ Abt. für Plastische-, Hand-, Kiefer- und rekonstruktive Mikrochirurgie, BG Unfallklinik Murnau; ${ }^{2}$ Abt. für \\ Rückenmark- und Wirbelsäulenverletztungen, BG Unfallklinik Murnau, Germany
}

The vastus lateralis muscle- or musculocutaneous flap is a well established tool in the surgery of pressure sores of the pelvic region. Its size, its constant large axial vascular pedicle originating from the lateral circumflex femoral artery, and its ability to carry quite a large skin island from the distal lateral region of the upper thigh makes this flap a very versatile one in the management of difficult situations. The vastus lateralis flap allows the simultaneous closure of defects in the trochanteric and sacral region, a technique which has not been described previously. A pedicled vastus lateralis flap may be the only remaining local salvage procedure for defects due to obstruction of internal and external iliac arteries and aortobifemoral bypass surgery. This is another application which has not yet been described in the medical literature. The outcome of a series of 38 vastus lateralis flaps and the complications are shown. The follow-up period ranged from 3 months to 4 years. One flap was lost. More complications were seen at the donor site than at the reconstructed defect. In patients who may be able to walk or stand at a later date, potential impairment of these functions has to be considered. In our opinion, the vastus lateralis flap is an excellent tool for managing large tissue defects in difficult situations.

Keywords: vastus lateralis; muscle flaps; trochanteric; sacral pressure sores; vascular disorders in paraplegic patients

\section{Introduction}

The use of the vastus lateralis flap in the treatment of decubital ulcers was first described by Ger in $1976 .{ }^{1}$ In his publication and in several others that followed, the vastus lateralis was used as a muscle flap with split skin graft to cover complicated ulcers of the trochanteric, ischial and perineal region. ${ }^{2-5}$

Bovet and co-workers were the first to describe, that the vastus lateralis can be reliably dissected as a myocutaneous flap with a skin island on the distallateral thigh. ${ }^{6}$

This myocutaneous flap was used to cover trochanteric ulcers, ${ }^{6,7}$ Abu Jamra et al reported further applications in the gluteal and sacral region, but again, as a muscle flap. 8 In 1986 McCraw and Arnold in their Atlas of Muscle and Musculocutaneous Flaps reported, that the vastus lateralis flap usually cannot reach the sacrum. ${ }^{9}$

Drimmer and Krasna in 1987 used the myocutaneous vastus lateralis flap to cover defects of the trochanteric-, ischial and posterior thigh regions and stated: 'the length obtained with this technique probably will allow closure of groin and sacral wounds, although we have not used it as such. ${ }^{10}$

Correspondence: AB Schmidt
Again, in more recent publications the use of the vastus lateralis myocutaneous flap was also restricted to defects of the ischial, trochanteric, and occasionally groin and pelvic regions. ${ }^{11,12}$

Musculocutaneous flaps are generally accepted as the best way to achieve durable closure of large pressure sores. $1,3,9,11$ In this context, the vastus lateralis flap is only considered when all other, more simple alternatives have been exhausted. ${ }^{9-11}$ Therefore, the vastus lateralis flap has not been used routinely up to now. The ability to cover trochanteric and sacral pressure sores simultaneously is a technique that was described by the first author. ${ }^{13}$ Another important application is the cure of extensive gluteal defects following occlusive disease of the aortic bifurcation and aorto-bifemoral bypass grafts. This application has not previously been described by other authors. The purpose of this paper is to promote the use of this extremely useful flap for difficult situations, and to present our experience with a series of 38 flaps.

\section{Materials and methods}

From 1988 to 1995 we performed 38 pedicled vastus lateralis flaps to cover various defects. The youngest patient was 17 years and the oldest 72 years. Average 
age was 43 years. In half of the patients the vastus lateralis was used as a myocutaneous flap, in the other half only the muscle was used.

The indications for the procedure were:

(a) Infection after a Girdlestone procedure: (nine in paraplegic patients)

(b) Gluteal defect following a high voltage electrical burn:

(c) Pressure sores

Ischial:

Trochanteric:

Sacral (obstruction of both iliac aa.)

Trochanteric and sacral combined:

Trochanteric and ishial combined:

The electrical burn patient died from multi-organfailure 1 week postoperatively. In the case of sacral sores associated with bilateral iliac artery occlusion, perfusion of the lateral circumflex femoral artery had been reestablished by aortobifemoral or aortofemoral bypass surgery. In three of these patients, bypass grafting itself had led to complete obstruction of the iliac vascular bed.

The operative technique has been well documented in previous publications and is not described again here. The description of the technique by Bovet et al is recommended for reference. ${ }^{6}$

The operations were performed with the patient in a lateral position; excision of the ulcer and flap dissection were performed according to the general rules of decubital ulcer surgery. ${ }^{11,13}$ Postoperatively, the patients were nursed in an airfluidized or lowflow bed. Mobilisation in a wheelchair or on crutches was started between the end of the 2nd and the 4 th week depending on the clinical situation.

\section{Results}

Healing was uneventful in the majority of the patients. The complications seen are set out in Table 1 .

Impaired wound healing at the recipient site required operative revision in seven patients; in four, complications affected the section of the donor site covered with split skin graft over the lateral femoral condyle. Multiple (up to three) complications occurred in four patients. In all other 24 patients, healing was

Table 1 Pedicled Vastus Lateralis Flap $(n=38)$

\begin{tabular}{lc}
\hline Complications:(Follow up 4-48 months, av.=14 months) \\
\hline Flap necrosis: & 1 \\
Partial flap-loss & 1 \\
Delayed healing recipient site: & 7 \\
Delayed healing donor site: & 4 \\
Recurrence of pressure sore: & 1 \\
Recurrence of osteitis (Girdlestone): & 2 \\
Pain of donor site in rehabilitation: & 1 \\
\hline
\end{tabular}

uneventful. Nevertheless the rather high complication rate is related to the unusually high morbidity of these patients. Common pressure sores are not indications for the vastus lateralis flap.

\section{Case reports}

Two case reports illustrate new uses of the vastus lateralis flap: the simultaneous cover of a trochanteric and a sacral ulcer (case 1), and the reconstruction of a huge soft tissue defect in the ischial and gluteal region following aortobifemoral bypass surgery (case 2).

\section{Case 1}

A 51-year old patient from Tanzania had a road traffic accident 1 year prior to admission and was paraplegic below TH 10. Treatment in his country was complicated by a severe infection with malaria followed by the development of extensive decubital ulcers over the trochanter and the sacral bone. After transfer to our hospital, the general condition of the patient had to be stabilised with treatment of the malarial infection and conservative treatment of the pressure sores. Repair of all defects was achieved by a one stage procedure. Excision of the ulcers was followed by elevation of a musculocutaneous vastus lateralis flap with a large, very distally placed skin island. The skin between both ulcers was undermined at fascial level and the flap was fed through this tunnel so that the proximal muscle covered the extensive trochanteric ulcer completely and the distal muscle and the skin island filled the defect over the sacrum. The donor site at the distal lateral thigh and the muscle surface over the trochanter were covered with split skin grafts. Postoperatively, the patient was nursed on an airfluidised bed. Healing was uneventful. A stable cover of both pressure sores and of the donor area was achieved (Figures 1-3).

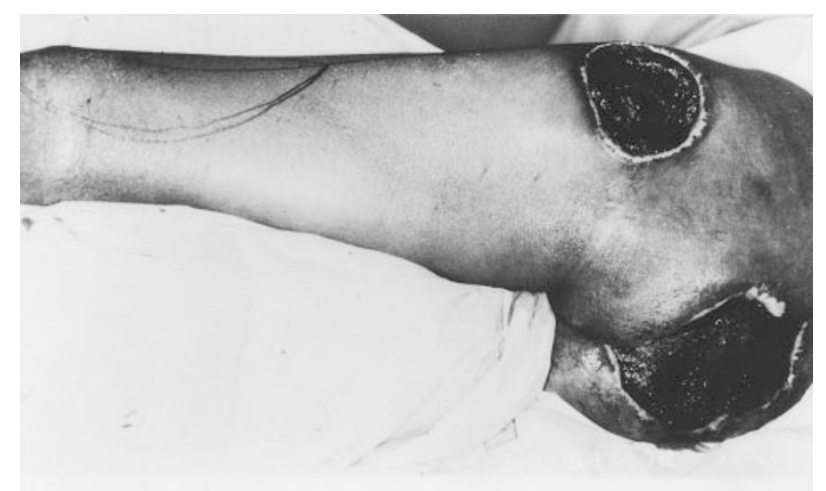

Figure 1 Extensive decubital ulcer over the left trochanter and sacral bone with wide undermining. Pressure sores dyed with methylenblue. Marking of the vastus lateralis skin island over the lateral distal thigh and knee region on the left 


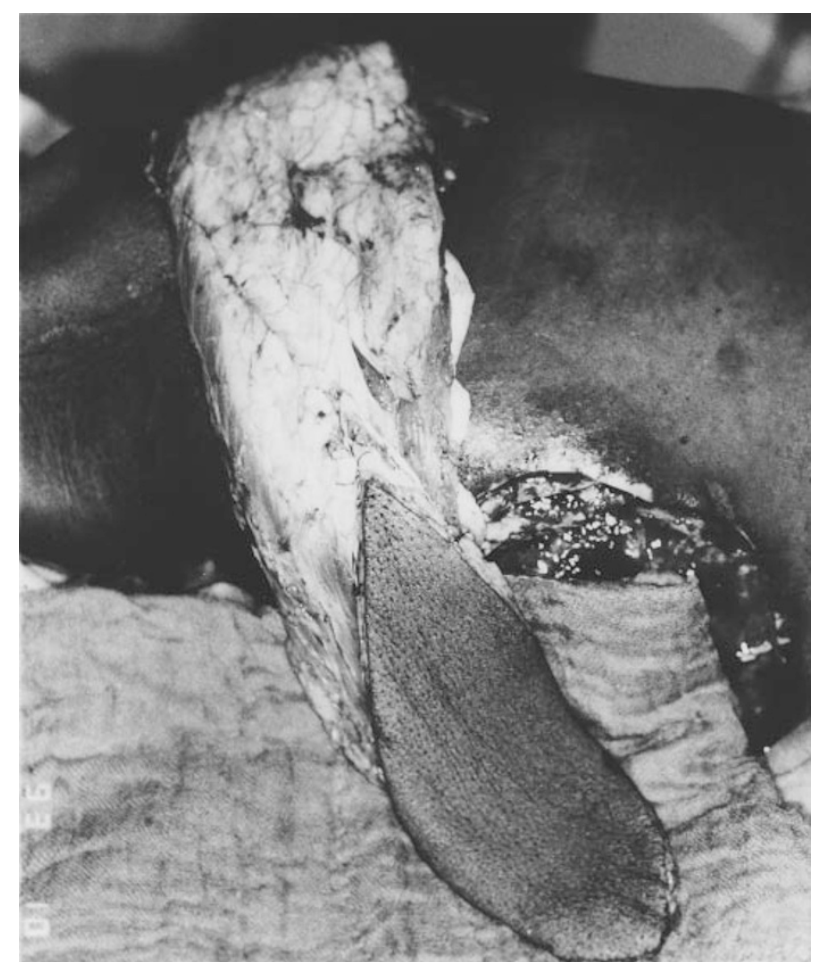

Figure 2 Completed dissection of vastus lateralis flap with very distal skin island. To demonstrate the arc of rotation the flap has been draped across the trochanter onto the sacral ulcer and reaches and fills both lesions with ease

Case 2

A 48-year old man had been paraplegic below TH 5 for 11 years. Being a heavy smoker, he developed an occlusion of both iliac arteries. This was bypassed by an aortobifemoral trouser graft, which led to a complete loss of the remaining collateral perfusion in the iliac region (Figure 4). After bypass surgery, the left femoral artery did not regain sufficient flow making above-knee amputation unavoidable. Sufficient perfusion of the right leg was achieved at the additional cost of a very large area of soft tissue necrosis with loss of the remaining remnants of the gluteal muscles. Angiography showed a good perfusion of the right lateral circumflex femoral artery, including the descending branch (Figure 6), allowing the decision to perform a pedicled musculocutaneous vastus lateralis flap. It was dissected as an island flap (Figure 5) and was advanced into the defect through a prefascial tunnel. Complete closure of the defect was possible using this flap and an additional local flap at the left gluteal border. Small areas of delayed wound healing at the donor as well as at the recipient site healed under conservative treatment on an airfluidised bed. Interestingly a control-angiogram half a year after the operation revealed the descending branch of the lateral circumflex femoral artery now stronger in size. The curved course around the femoral condyle is

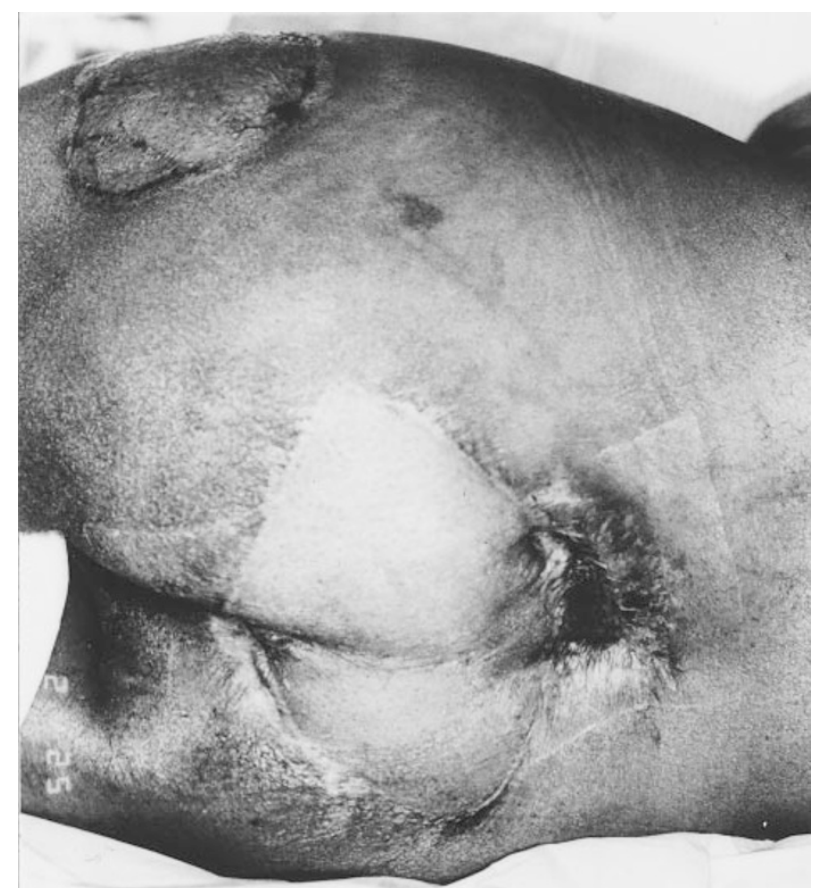

Figure 3 Healed skin island of the vastus lateralis flap covering a large sacral decubital ulcer, and (top) trochanteric region with healed split skin graft

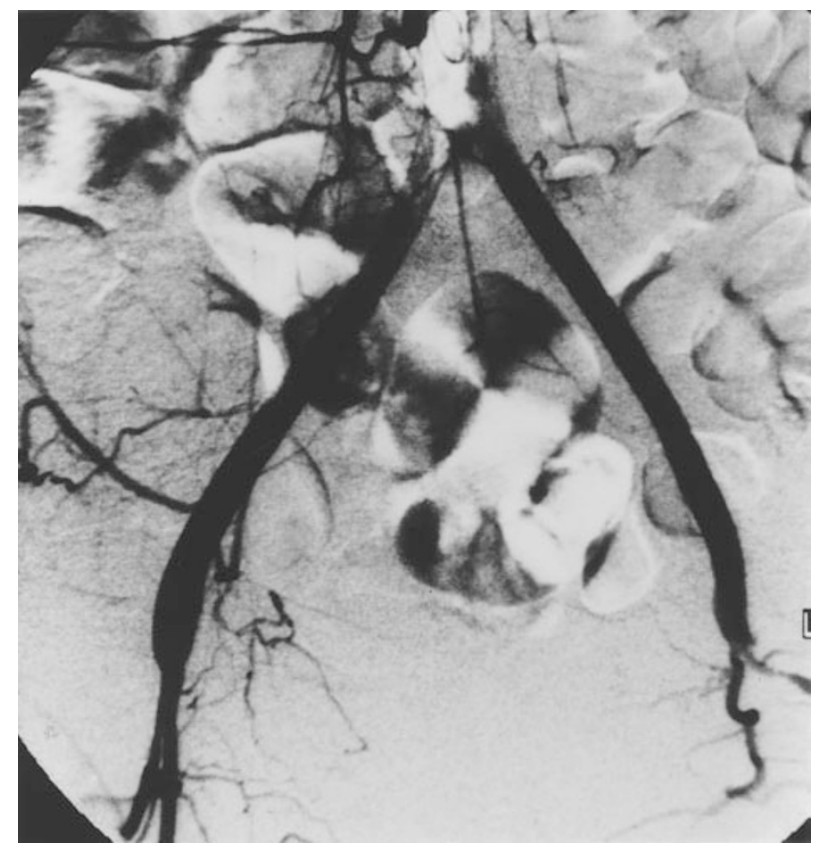

Figure 4 Angiography showing the aortobifemoral bypass graft, good perfusion of the right femoral artery (left), and non-existant perfusion of the left leg (right). This leg had to be amputated 


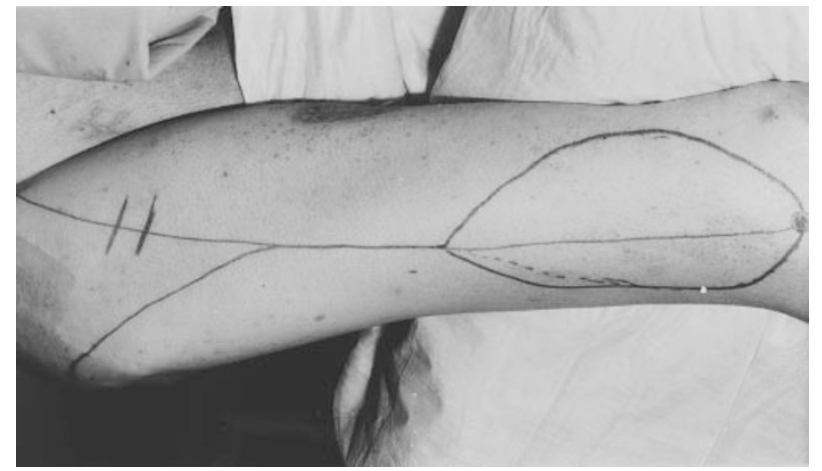

Figure 5 Markings for vastus lateralis flap with large distal skin island on the remaining right leg. On the left: marking of expected entry of lateral circumflex femoral artery $10-12 \mathrm{~cm}$ below anterior superior iliac spine

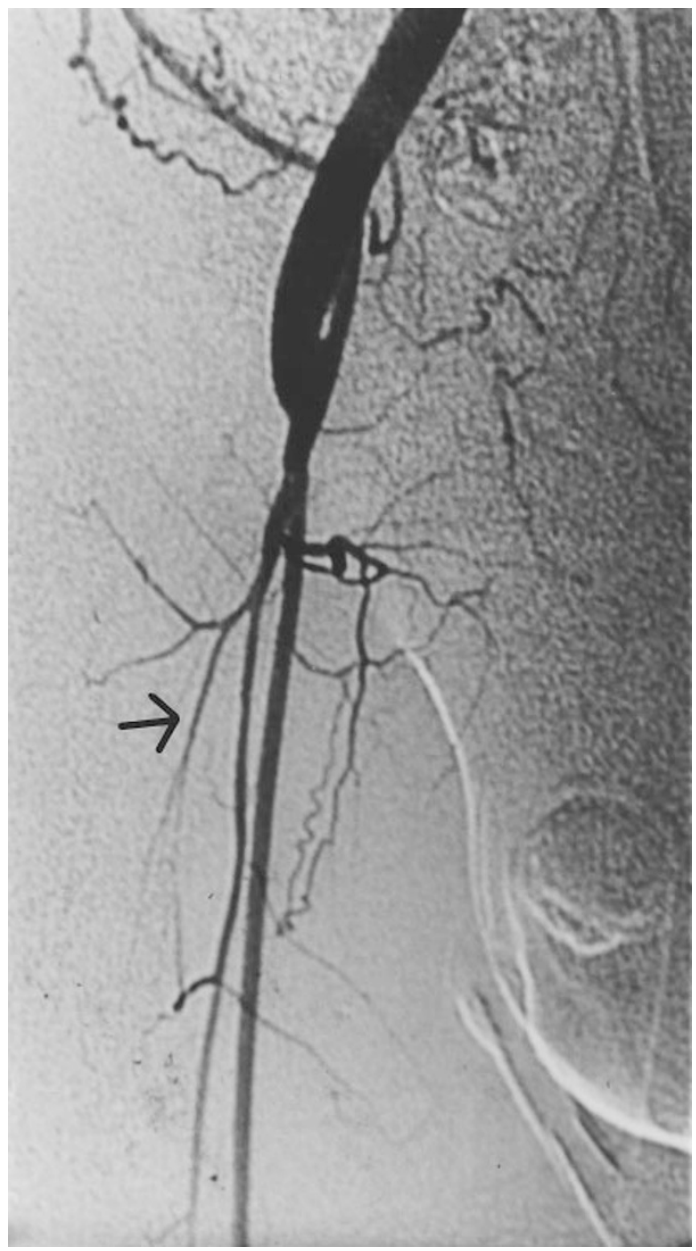

Figure 6 Preoperative angiography, showing the aortobifemoral graft, the lateral circumflex femoral artery with its descending branch marked with an arrow

well documented (Figure 7). Five years after the operation the patient is free of recurrence, and is mobilised in a wheelchair (Figures 4, 5, 6 and 7).

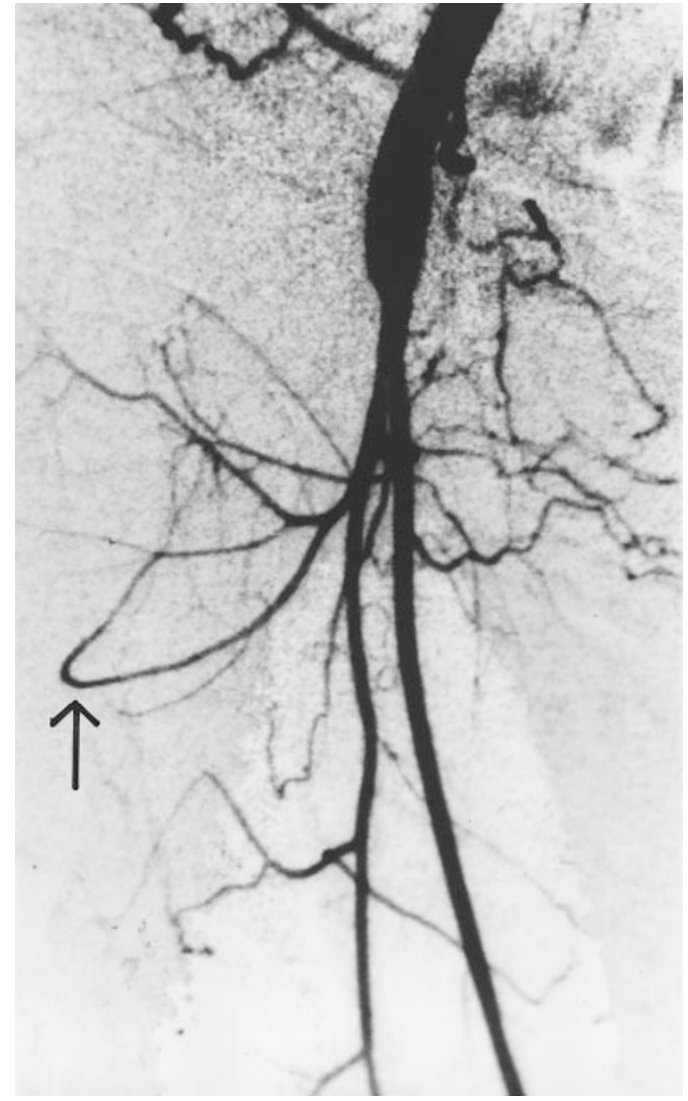

Figure 7 Half a year later, the descending branch appears to have increased in size and takes its new course around the trochanter in a dorsal direction. This is an indication of a stronger flow supplying the presacral region

\section{Discussion}

Since the first reports by Ger in $1976^{1}$ the vastus lateralis muscle and musculocutaneous flap has achieved a sound position in plastic and reconstructive surgery of the pelvic region. ${ }^{2-14,18}$

There is no disagreement among all authors, that the vastus lateralis muscle flap is the best solution to heal infected cavities due to infected hip joints or hip joint replacement. ${ }^{5,11,14-19}$

Mobilisation of the vastus lateralis muscle on a distal pedicle and its use to cover defects around the knee was described by Swartz et al. in $1987 . .^{20}$ This application did not become popular.

The so-called anterolateral thigh-flap represents the latest development of the vastus lateralis flap. It is mainly used as a microvascular flap and was first described by Song and co-workers in $1984 .^{21}$ The anterolateral thigh-flap contains as little vastus lateralis muscle as possible. It can be used for reconstructive purposes all over the human body. ${ }^{21-26}$ This further development of the descending branch of the lateral circumflex femoral artery as a flap pedicle does not seem to be of major 
importance for the treatment of decubital ulcers. However, the preparatory anatomical studies and the refinements of the operative technique are essential for the understanding of the blood supply to the skin of the relevant thigh region and improve the operative technique of the myocutaneous vastus lateralis flap.

Due to the demanding nature of the operation, the blood loss involved and the unsightly donor defect this flap only gets used when all other choices have been exhausted. $4,9,11,12$ Although the functional loss of vastus lateralis can be compensated even by nonparalysed patients, ${ }^{27}$ the flap will mainly be used in patients with paraplegia or tetraplegia. The vastus lateralis flap represents the classical salvage procedure to deal with a second, third or later recurrence of a pressure sore, a situation where all conventional flaps are no longer possible. In selected cases, this operation can avoid having to use the mutilating procedure of a total thigh flap, which entails loss of the leg and its sitting surface. ${ }^{28}$

Vastus lateralis is the only myocutaneous flap to reach all three typical decubital ulcers of the pelvic region simultaneously. The flap is ideally suited to replace large volumes of soft tissue loss following aorto-bifemoral bypass grafting for occluded external and internal iliac arteries.

The one flap loss in our series was due to a twisted pedicle which was not noticed in time because the muscle flap was buried.

According to our experience, a vastus lateralis flap can be used even after longstanding paraplegia because complete atrophy and fibrous change of the muscle is very rare. Usually, a hypotrophic but still suitable muscle for flap transfer can be dissected.

Some problems occurred at the split skin grafted donor defect over the lateral aspect of the knee, although all cases healed eventually. Recent flap developments concerning the descending branch of the lateral circumflex femoral artery involved a refinement of the known operative technique. Anatomical studies in preparation of perforator-based flaps allowed the dissection of a vastus lateralis skin island extending far more proximally than Bovet and coworkers ${ }^{6}$ originally considered safe into a territory that was thought to belong to tensor fasciae latae. The practical consequence is that the vastus lateralis muscle can be dissected including a very large area of skin. $22-24$

\section{Conclusions}

The musculocutaneous vastus lateralis flap has become very important in the treatment of complicated recurrent pressure sores and defects after vascular occlusion at iliac level. The disadvantages of some loss of blood and a slightly difficult dissection technique are outweighed by the advantages of a big arc of rotation and the fact that this flap is still available despite multiple previous operations.
The exact knowledge of this flap seems essential for every center for paraplegic patients.

\section{References}

1 Ger R, Levine SA. The management of decubitus ulcers by muscle transposition. Plast Reconstr Surg 1976; 58: 419-428.

2 Minami RT, Hentz VR and Vistnes LM. Use of the vastus lateralis muscle flap for repair of trochanteric pressure sores. Plast Reconstr Surg 1977; 60: $364-368$.

3 Mathes SJ, Nahai F. Vastus lateralis muscle flap. In: Clinical Atlas of Muscle and Musculocutaneous Flaps. Mosby: St Louis 1979 , pp. $51-61$.

4 Dowden RV, McCraw JB. The vastus lateralis muscle flap: Technique and applications. Ann Plast Surg 1980; 4: 396-304.

5 Mathes SJ, Nahai F. Vastus lateralis. In: Clinical Applications for Muscle and Musculocutaneous Flaps. Mosby: St Louis, 1982, pp. $62-63$ and $444-446$.

6 Bovet JL, Marcondes Nassif T, Guimberteau JC, Baudet J. The vastus lateralis musculocutaneous flap in the repair of trochanteric pressure sores: Technique and indications. Plast Reconstr Surg 1982; 69: 830-834.

7 Hauben DJ Smith AR, Sonneveld GJ, Van der Meulen JC. The use of the vastus lateralis musculocutaneous flap for the repair of trochantic pressure sores. Ann Plast Surg 1983; 10: 359-363.

8 Abu Jamra FN, Afeiche N, Sumrani NB. The use of a vastus lateralis muscle flap to repair a gluteal defect. Br J Plast Surg 1983; 36: 319-321.

9 McCraw JB, Arnold PG. Vastus lateralis. In: Atlas of Muscle and Musculocutaneous Flaps. Hampton Press: Norfolk 1986, pp. $463-472$.

10 Drimmer MA, Krasna MJ. The vastus lateralis myocutaneous flap. Plast Reconstr Surg 1987; 79: $560-566$.

11 Lüscher NJ. Muskulokutaner Vastus lateralis-Lappen. In: Dekubitalulzera der Beckenregion. H. Huber: Bern 1989, pp. $134-138$

12 Waterhouse N, Healy C. Vastus lateralis myocutaneous flap for reconstruction of defects around the groin and pelvis. Br J Surg 1990; 77: $1275-1277$.

13 Schmidt A, Herndl E. Behandlung des sakralen Dekubitus. In: Mühlbaur W. (ed) Dekubitalgeschwüre Marseille: München 1989, pp. $81-89$.

14 Arnold PG, Witzke DJ. Management of failed total hip arthroplasty with muscle flaps. Ann Plast Surg 1983; 11: 474478.

15 Eltorai I. The girdlestone procedure in spinal cord injured patients. A ten year experience. $J$ Am Paraplegia Soc 1983; 6: $85-$ 86.

16 Collins DN, Garvin KL, Nelson CL. The use of the vastus lateralis flap in patients with intractable infection after resection arthroplasty following the use of a hip implant. J Bone Joint Surg 1987; 69A: $510-516$.

17 Klein N, Moore T, Capen D, Green S. Sepsis of the hip in paraplegic patients. J Bone Joint Surg 1987; 70A: 839-843.

18 Meland NB, Arnold PG, Weiss HC. Management of the recalcitrant total-hip arthroplasty wound. Plast Reconstr Surg 1991; 88: $681-685$.

19 Evans GR et al. Joint communication with pressure sore: The refractory wound and the role of girdlestone arthroplasty. Plast Reconstr Surg 1993; 91: 288-294.

20 Swartz WM, Ramasastry SS, McGill JR, Noonan JD. Distally based vastus lateralis muscle flap for coverage of wounds about the knee. Plast Reconstr Surg 1987; 80: 255-263.

21 Song YG, Chen GZ, Song YL. The free thigh flap: A new free flap concept based on the septocutaneous artery. Br J Plast Surg 1984; 37: $149-159$

$22 \mathrm{Xu}$ DC et al. Applied anatomy of the anterolateral femoral flap. Plast Reconstr Surg 1988; 82: $305-310$.

23 Koshima I, Fukuda H, Utunomiya R, Soeda S. The anterolateral thigh flap; variations in its vascular pedicle. Br J Plast Surg 1989; 42: $260-262$ 
24 Zhou $\mathrm{G}$ et al. Clinical experience and surgical anatomy of 32 free anterolateral thigh flap transplantations. Br J Plast Surg 1991; 44: $91-96$.

25 Wolff K-D, Grundman A. The free vastus lateralis flap: An anatomic study with case reports. Plast Reconstr Surg 1992; 89: $469-477$

26 Wolff K-D, Howaldt H-P. Three years of experience with the free vastus lateralis flap: An analysis of 30 consecutive reconstructions in maxillofacial surgery. Ann Plast Surg 1995; 34: 35-42.

27 Murray MP, Jacobs PA, Mollinger LA, Gore DR. Functional performance after excision of the vastus lateralis and vastus intermedius. J Bone Joint Surg 1983; 65A: 856-859.

28 Berger SR, Rubayi S, Griffin AC. Closure of multiple pressure sores with split total thigh flap. Ann Plast Surg 1994; 33: $548-$ 551 